\title{
CARE OF SPINAL CORD INJURIES IN THE ARMED FORCES OF INDIA
}

\author{
By Lt. Col. A. S. Chahal, M.S., F.R.A.C.S. \\ Spinal Cord Injury Centre, Military Hospital Kirkee, Pune-20, India
}

\section{INTRODUCTION}

ONE in three injuries of the spine is associated with injury to the spinal cord. With the rapid industrialisation, the motor vehicular traffic has increased. Speed of road transport has also been on the increase thus leading to more road accidents, a price every nation pays for fast moving traffic on its roads. Armed Forces have also undergone a change and are more mobile and mechanised. There are more vehicles carrying troops and equipment from one place to another. Most of our peace time spinal cord injuries come from these accidents. Fall of heavy weights on the back and sports account for the rest. During the Indo-Pak Conflict of I97 I we had 45 spinal cord injuries of war including I I Mukti Bahini volunteers of Bangla Desh.

Paraplegics have not received adequate attention of doctors and health services in our country. Even today very few states have well-organised paraplegic centres. Military Hospital Kirkee is a general hospital of 600 beds. It has a 200-bedded Orthopaedic Centre. Armed Forces organised paraplegic units of 30 beds each at Lucknow and Poona after 1965 Indo-Pak Conflict. These units were attached to neurosurgical centres under the care of neurosurgeons. Twenty-two war casualties had paraplegia in the 1965 conflict. In 1968, rehabilitation of paraplegics was organised by shifting the 30-bedded unit from Military Hospital Poona to Military Hospital Kirkee where facilities for vocational training were available at the adjoining Queen Mary's Technical School. In 197I, it was reorganised to a Ioo-bedded spinal cord injury centre. By end of December I97I, we had 92 patients at our centre, who have since undergone a total medical care and rehabilitation at this centre. There were initial problems of staff and equipment to cater for these severely disabled patients which have now been overcome. Today the centre offers a total medical care from the acute stage, soon after injury, to the time of discharge. This has been possible with the active support from both our DG AFMS and Director of Medical Services. Paraplegics not only need medical care but attention to their socio-psychological problems which can be attended to by an efficient administration supporting therapautic measures.

\section{ORGANISATION AND CARE AT THE SPINAL CORD INJURY CENTRE}

Our patients came from all over the country where troops are posted. After first-aid and initial medical care, paraplegics are evacuated by various military hospitals to Spinal Cord Injury Centres. However, tetraplegics, due to the more 
serious nature of their injury and respiratory complications, are attended to for the first few weeks at Command Hospitals and when their condition has stabilised are transferred to the Spinal Cord Injury Centre. At the centre, care is divided into three phases:

Phase I. Fresh paraplegic/tetraplegic is admitted to Spinal Cord Injury Ward I of 24 beds. There are six nursing officers with adequate para-medical staff to attend to these acutely ill and seriously disabled patients. Regular two hourly turning is carried out by trained teams of three male attendants with a nursing officer as team leader during day and night. Urinary bladder is under the personal care of the ward medical officer assisted by the nursing staff. All patients are treated by an indwelling Gibbon's catheter changed by the medical officer once a week with strict asepsis. After Io to 12 weeks, the neurogenic condition of the bladder is assessed and bladder training programme is started by intermittent catheterisation with percussion/compression at regular intervals in between the catheters. Bed side physiotherapy with stress on development of upper limbs and chest is started from the beginning. After I2 to I4 weeks, most of the fractures and dislocations of the spine are stable. These patients are now fit to sit in wheelchair and attend physiotherapy and occupational therapy in the departments.

Phase II. After I6 to I8 weeks the patient has learned to take care of his bladder and skin. He is fit for transfer to Spinal Cord Injury Ward II. Emphasis is now given to physical therapy. Patients learn to sit and transfer themselves from wheelchair to bed and vice versa. Regular active exercises are carried out in groups under the supervision of a physiotherapist. Sports like javelin throwing, putting the shot, wheelchair races and weight lifting form an integral part of therapy. Swimming is encouraged and patients are sent in batches to the Artificial Limb Centre's swimming pool. Our paraplegics have won awards in international and national Olympic for the Paralysed. Sports open a new avenue of physical and mental activity in the dull life of paraplegics.

Occupational therapy is vigorously pursued at this stage. Occupational therapists give the tetraplegics treatment to regain the lost function of their hands. They help them with appliances like spoon and pen attachments for feeding and writing. Paraplegics are assessed for their future vocational training programme. Any development of urinary infection or sore or other complications is not only detected early by regular inspection but treated vigorously before it becomes chronic. After 20 to 24 weeks most paraplegics become independent in self-care. They can bathe and dress themselves. They attend to their bladders and bowels regularly. They turn themselves in bed. They are now fit for transfer to Spinal Cord Injury Ward III.

Phase III. In this phase, a paraplegic is well rehabilitated and is least dependent on the staff. He now lives in a community or group who are planning to go home in the near future. At this stage they undergo vocational training in various trades like tailoring, radio repairing, hosiery or typing at Queen Mary's Technical School. Thus he spends four to six hours in the school daily and continues group physical therapy in hospital. This gives him confidence that he can look after himself and can do some work and be a productive member of the society. This is not only helpful in adding to his pension but gives him the rightful place in society. He is no longer a burden to his family or society but a healthy member contributing his share to the family. During this period if seats 
are available in Queen Mary's Technical School hostel he is discharged to continue his training at the school to lead an independent life. We have been able to rehabilitate 30 per cent of these trained paraplegics into suitable jobs.

\section{REHABILITATION IN CIVIL LIFE FOR PARAPLEGIC EX-SERVICEMEN}

Despite the various Government orders, the employers in industry are not keen to have disabled workers on their rolls when healthy adults are available in scores for each job they advertise. Another reason discouraging paraplegics from accepting a job is the lack of housing facilities in cities, in the vicinity of factory or workshop. Distances from place of residence to work are also a hindrance. Under a new scheme, each paraplegic serviceman is given a hand-propelled tricycle to improve his mobility and thus help him to travel to his place of work. Motorised tricycles in big cities and towns will help them to travel distances of five to ten kilometres with ease.

To start with our patients had a wooden chair with wheels. We could not afford to import the standard folding wheelchair for our patients. We have now developed a folding chair with brakes which meets the requirements of paraplegics. It is heavy and front castors need improvement but is better than the old models. Hand-propelled tricycles have been developed and improved in design. The latest model is light and patients can drive it at a speed of I5 to $18 \mathrm{~km}$. per hour comfortably. Cost of this tricycle is Rs. I400/-. By spending another Rs. 1000/- a scooterate engine can be fixed which gives this machine a speed of 25 to $30 \mathrm{~km}$. an hour. For one litre of petrol, it runs 60 kilometres. In a country like ours where we cannot afford a car for our paraplegics, suitable cheap transport is an essential part of rehabilitation equipment. We are issuing a hand-propelled tricycle to every paraplegic on discharge from hospital.

A large number of our soldiers come from villages and hilly areas where there are no roads or facilities to lead a wheelchair life. Tetraplegics need constant attention and medical care which is not available in their homes. For this group paraplegic homes are required. One such home has been constructed for 25 patients next to our hospital. A similar home near Delhi will look after paraplegic exservicemen from Northern India. At present they are being housed in Cheshire Homes at Delhi and Dehra Dun. Red Cross home Bangalore has been the only institution for last two decades which has provided shelter to disabled servicemen so far.

In our follow-up study we found that our paraplegics are handicapped by the long distances and lack of medical facilities in villages and countryside. For successful rehabilitation, we felt the need of homes for this social group where they can comfortably live and get prompt medical aid. Besides the sheltered workshop in the home, it provides occupation and work which is not available in their individual homes. Paraplegic home Kirkee is being developed as an example where the industrial complex nearby has got the potential to absorb our paraplegics into suitable jobs or modify the working conditions to suit them. This is a great step forward in the future rehabilitation of our paraplegics. A swimming pool, basketball ground and stadium is to be developed in this complex in the second and third phase when more accommodation will be built to house roo paraplegics in this home. 
During the last five years 210 paraplegics and tetraplegics have undergone treatment at our centre. One hundred and twenty-five have been discharged to homes after successful rehabilitation. Although the centre is primarily meant for traumatic paraplegics, seven to eight non-traumatic cases are also admitted annually for medical rehabilitation. During 1973 we had 36 fresh admissions of spinal cord injuries and there were no fatalities in this group.

\section{SUMMARY}

Development of Spinal Cord Injuries Centre in the Armed Forces of India has been discussed. Starting from a 30-bedded unit in 1965 we have now a I00bedded spinal cord injury centre, a major rehabilitation centre managed by trained medical staff for these patients. A 25-bedded paraplegic home for ex-servicemen has been recently built with modern facilities and amenities. Medical rehabilitation and vocational services are now available to paraplegics in a radius of one kilometre at this centre. 